\title{
Approaches to Cloud Computing in the
}

\section{public sector: case studies in UK Local}

\section{Government}

\section{ABSTRACT}

This chapter considers the key characteristics of cloud computing, which is defined as a scalable network infrastructure where consumers receive IT services such as software applications and data storage through the Internet on a subscription basis. It reviews what are considered to be the general benefits to client organisations of utilizing cloud supplied IT services. These include long-term cost savings, simpler client owned IT infrastructure and reduced energy consumption through utilisation of more efficient supply-side infrastructure. The chapter then focuses on the potential for use of cloud based services in Central and local government in the UK, and to what extent these are already being considered. As part of this appraisal by government, concerns have been raised over issues such as security, access, data protection and ownership, and this chapter seeks to interrogate the perceived positive and negative drivers to local government cloud utilisation using a conceptual framework and case studies of four London borough councils. It reveals that the concept of cloud computing is new and not clearly understood within UK local government. Local authorities, who face further cuts in government funding despite the wider economic recovery, welcome a cloud-based IT infrastructure which may lead to considerable savings. Yet government is institutionally conservative with a risk-adverse attitude, so local authorities are more likely to adopt a hybrid approach to the implementation of cloud computing strategies. Concerns over data security and privacy may be overcome through careful compliance with relevant laws and standards. Keywords: Cloud Computing, local government, government IT, IT innovation, business process change, G-Cloud, data protection and data privacy

\section{INTRODUCTION}

Cloud computing is held to offer a number of advantages to the organisations which utilise it. These include cost savings, scalable computing services, simpler IT infrastructure and reduced energy consumption. Theoretically the advantages offered are as relevant to public sector organisations as they 
are for the private sector. Within local government there are pressures, positive and negative, from a decline in IT budgets, a lack of adequate skills in public sector employees and from the centrally imposed e-Government agenda. As a result cloud-based delivery models are rapidly gaining the attention of government. Across the public sector, many IT leaders are carefully considering the implications of cloud utilisation. Software applications, hardware, infrastructure, platforms, services and storage or whether the government should develop its own cloud are issues which require careful consideration. Key concerns include issues such as the security and ownership of data, potential impact on employment within the client organisations and the structural and cultural implications of moving to cloud provision for large, complex and conservative government institutions. As yet, very little research has been carried out on the implications of utilising cloud services for local government. This study, through theoretical analysis using a conceptual framework and four case studies of London-based borough councils, attempts to explore the likely impact of cloud computing use within local authorities. Firstly, the conceptual framework is presented in the context of current literature relating to the subject. This will consider aspects such as driving and resisting forces and potential implementation issues arising within the public sector. Following on from this theoretical discussion case study data from the four boroughs will be analysed using the same framework considerations. Conclusions will be drawn and consideration given to potential next-steps in this specific field of research.

\section{THE CONCEPT OF CLOUD COMPUTING}

Cloud computing is a style of computing where IT capabilities are provided as a service delivered over the Internet to a customer's workplace, similar to utilities such as water and electricity which are 'piped' to the customer's premises. Although there is no universally agreed definition, cloud computing has five key attributes according to a group of researchers at Gartner: service-based, scalable and elastic, shared, metered by use and using Internet Technology (Plummer et al, 2009). These attributes are addressed as 'essential characteristics' by the National Institute of Standard and Technology (NIST, 2011).

The key advantages of cloud computing are held to be reduced costs, increased efficiency and a significant reduction in energy consumption leading to cost savings and greener IT (Catteddu, 2010; Armbrust et al, 2010; Foster et al, 2008; Luis et al, 2008; Aymerich et al, 2009; Grossman, 2009; Korri, 2009; Maggiani, 2009; Nelson, 2009). For potential customers cloud computing presents an attractive alternative to buying, setting up and maintaining their own in-house computing infrastructure (Korri, 2009). These advantages are theoretically as applicable to the public sector as to private organisations, and as set out in the Digital Britain (2009) report, the UK government sees the adoption of cloud computing as critical to the success of its plans to increase efficiency in the public sector. 
In the private sector, concerns have been expressed both about the security of data management and loss of organisational control of a key resource (Takabi et al, 2010; Buyya et al, 2009; Grossman, 2009). Public sector clients (or potential clients) will be aware of these concerns. Given the confidential and sensitive nature of much of the data held by public institutions, this becomes a particularly important issue (Nelson, 2009).

So in considering the public sector use of cloud computing we see there are opposing forces; potential cost and efficiency savings verses potential, but difficult to quantify, risks to data security.

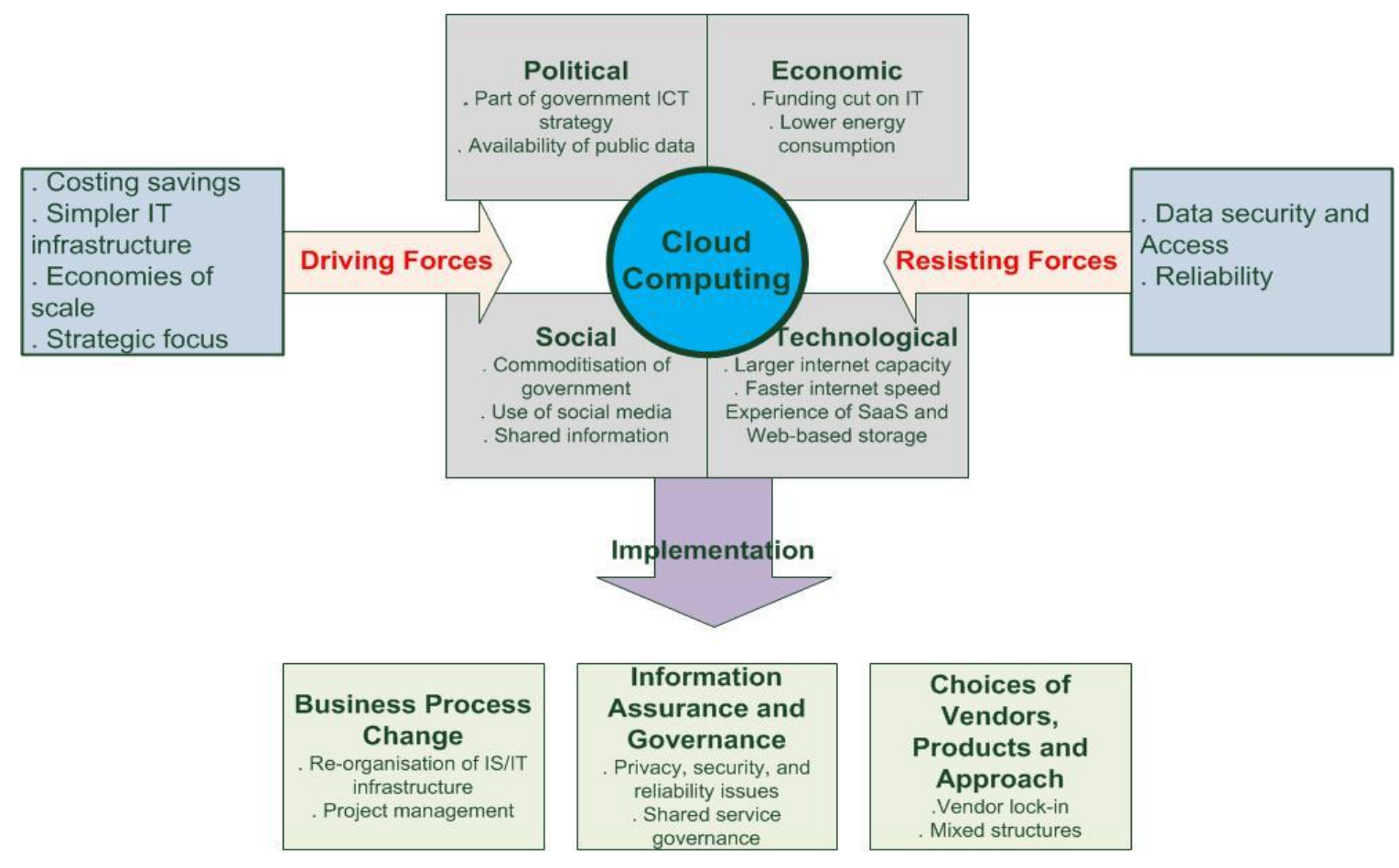

Figure 1: A conceptual framework of implementing cloud computing in local government (Chang, 2011)

\section{THE CONCEPTUAL FRAMEWORK FOR IMPLEMENTING CLOUD COMPUTING IN LOCAL GOVERNMENT}

The conceptual framework (Figure 1) draws on two models for analysing the change process: Lewin's model (Lewin, 1947) and the PEST model which sorts attributes and consequences by four types: political, economical, social and technological. In the framework the key elements commonly associated 
with cloud computing, or commonly understood to be attributes or consequences of cloud computing implementation, are categorised using PEST. This provides a general background and sets out the relevance of cloud computing for government organisations. On top of this, through applying Kurt Lewin's change process model, driving forces and resisting forces are identified. This framework was developed as part of a theoretical paper (Chang, 2011) before the current empirical study was devised.

There are three client-side activities involved in the implementation of cloud computing; business process change, information assurance and governance, and choice of vendors, products, platform and approach. These implementation activities also form part of the conceptual framework.

\section{Background}

In the UK public sector the move towards cloud-based services is largely driven by the Westminister government's strategies for centralising ICT resources and for making more public services directly available online (Cabinet Office, 2010). It has been predicted that the adoption of the government cloud, known as the G-Cloud would result in some $£ 3.2$ billion savings. G-Cloud is considered to be an innovative development to meet demand for greater efficiency and a simpler IT infrastructure in the current economic situation where, even as the mainstream economy recovers, it is considered prudent policy to maintain low public spending, or even reduce it further. Government agencies need to prioritise their IT services and explore shared platforms, such as the public cloud, in order to achieve the required cost savings. They will have to focus their IT spend on mission-critical business areas (Das et al, 2011; Di Maio, 2009).

Using public cloud services to host public data which can be accessed through social media is an important trend that will have a significant impact both on citizen service delivery and on the government workplace. Cloud computing and the development of G-Cloud will inevitably accelerate and open up such communication channels, and government IT leaders need to consider the associated issues such as security, potential loss of control and accountability for data recovery.

Government agencies have experienced a range of IT solutions over past years including outsourcing, grid computing, SaaS, virtualisation and Web-based storage. These form a foundation for the implementation of cloud computing. Additionally, larger internet capacity and speed nowadays will ensure reliant and appropriate cloud service delivery. 


\section{Driving forces}

There are four significant driving forces that may act on local government IT leaders, prompting them to consider cloud computing and encouraging them forward during analysis of their IT options. These driving forces are cost savings, simpler IT infrastructure and flexibity, economies of scale and strategic focus.

\section{Cost savings}

The cloud computing client should benefit from reduced investment in IT and much smaller servicing and maintenance costs because the requirement for 'owned' or 'in house' IT hardware will drop significantly (Wyld et al, 2010; Vaquero et al, 2008). They will also benefit financially because running less hardware means reduced energy consumption (AbdelSalam et al, 2009). Cloud users can also utilise their remaining 'in house' hardware more efficiently (Aymerich et al, 2008) thus freeing up internal resources.

\section{Simpler IT infrastructure/flexibility}

Cloud computing services are delivered through the Internet so, as stated above, there is no need for the client organisation to own and run a large and complex IT infrastructure. There is no need for capacity for changes in usage or software/technology. The cloud is easily flexible, providing an inherent ability to scale computing power up and down according to usage (Armbust 2010; McEvoy \& Schulze, 2008). With cloud-based software services clients do not need to worry about updating or maintaining software, or with licensing issues. These aspects are dealt with by the vendor (Vining \& Di Maio, 2009).

\section{Economies of scale}

Cloud vendors have typically been reputable enough to offer customers a reliable service because they are large enough to provide the necessary resilience. With their large data centres and extensive computing capacity cloud providers can enjoy economies of scale impossible for individual clients, yet the benefits can be passed on to those clients (Marston et al, 2011; Grossman, 2009).

\section{Strategic focus}

Having realised cost savings by using cloud based computing, and with a smaller in-house IT infrastructure, local authorities are able to re-focus their attention on strategic goals. Cloud computing should free them up to make better use of limited financial, IT and human resources (Low et al, 2011; Vining \& Di Maio, 2009). 


\section{Resisting forces}

At the same time there are significant resisting forces that local government must consider during analysis of their IT options, and which may ultimately prevent them from adopting cloud computing. These resisting forces are security and access, and reliability and trust.

\section{Security and access}

Customers of cloud computing do not know where the machines they use actually are. They do not know where their data is actually stored. Everything is somewhere in the cloud. This is a significant concern for local authorities because, to meet the requirements of current privacy legislation, government agencies must know exactly where their data is being stored and who is able to access it (Mishra et al, 2013; Buyya et al, 2008).

\section{Reliability and trust}

The successful implementation of cloud computing relies largely on the trust between buyers and vendors, so local authority clients will need reassuring as to the service they will receive. In particular the vendor has to provide assurance over data security and privacy issues, which must be carefully written into the service level agreements (SLAs) agreed between the parties (Moreno-Vozmediano et al, 2013; Kandukuri et al, 2009). The cloud supplier must use encryption technologies to protect data in shared environments (Younis and Kifayat, 2013; Vining \& Di Maio, 2009).

\section{Implementation issues}

So we see that local authorities should carefully consider the benefits and risks of adopting a cloud based service model, and this will include start-up and ongoing 'rental' costs as well as long term savings. They must also consider which of the several service models on offer is appropriate for their needs. Once the decision to proceed has been taken it is important that they implement cloud computing as a business process change project, which requires senior management support (Bojanova et al, 2013; Scholl, 2003). Concerns have already been raised that local government is not used to running large IT projects and therefore the project failure rates are high (Gilbert, 2009). In the public sector successful cloud computing implementation does not just depend on solving the technical issues, such as broadband bandwidths. It will have considerable impact on the authority's IT infrastructure, on its staff, both in terms of numbers and required skills, and on the authority's service users. These aspects all need to be addressed to achieve successful implementation, and decisions taken now will have implications for how local government provides services well into the future. 
According to Armbrust et al (2010) success in implementing cloud-based infrastructure depends on a careful comparative assessment of the various types of service delivery available, and the alternative price models. IT leaders should also consider the choice of public cloud or private cloud. Some of the pricing models on the market are quite complex and therefore total service costs may be difficult to predict. Vendor lock-in could potentially be a serious concern because it can be extremely difficult to change the interface when moving from one provider to another (Silva et al, 2013; Buyya et al, 2008). This may cause problems for authorities who have to comply with stringent public sector competition and 'value for money' tests. Another significant risk consideration will be future technology change costs if the provider discontinues the service (Foster et al, 2008).

Cloud computing generally is a relatively new service model. Considering this alongside the concerns over data security and privacy already discussed has lead to the suggestion that local government is more likely to adopt a staged approach to the implementation of cloud computing and to utilise a mixed service structure built on both public and private clouds (Tsohou et al, 2014; Di Maio, 2009).

\section{RESEARCH QUESTIONS}

Chang's conceptual model (Chang, 2011) sets out in theoretical terms the principle issues local authorities must address when considering cloud computing. By discovering some of the actual views and concerns held by real life stakeholders we can develop a more realistic assessment of potential implementation problems.

There are three main research questions:

1. To what extent are local authorities aware of cloud computing and the development of the government cloud (G-Cloud)?

2. What do stakeholders see as the main benefits for local authorities of adopting cloud computing and what do they see as the main disadvantages?

3. How might cloud computing be implemented by local authorities, in terms of business process change, information assurance and vendor selection?

\section{RESEARCH METHOD AND DESIGN}

As the aim of the research was to investigate key stakeholders' perceptions of cloud computing and the relative importance of contextual factors, a qualitative approach was used (Yin, 2009; O'Donnell \& Stewart, 2007). Case study analysis was undertaken at four London based local authorities to determine if they were planning to move to cloud service utilization, and if so, how they were planning to achieve this change. 
Interviews were held with the head of IT and members of the IT management team at each council between October 2011 and January 2012, seeking to gain a better understanding of how they viewed cloud service provision and the nature and purposes of the G-Cloud as well as opportunities for, and constraints on, its implementation in local authorities. The local authorities selected are all sufficiently large to be at the stage of considering cloud computing and may already have some experience of shared services. They were identified from press reports and government publications. Prior to commencing the interviewees were all give assurance that no mention would be made of their name or the organisation they represent in any of the findings/published material.

The results obtained from interviewing the four case study organisations have been comparatively analysed based on the conceptual framework previously proposed and using the three main research questions addressed in the study. The findings have then been analysed to identify the level of awareness of cloud computing in local government, perceived opportunities for its use, perceived constraints and threats and then to determine if there are any organisational factors which account for differences in response from one council to another. It will also be possible to gauge differences in central government's perception of the key issues and determine what actions need to be taken to address the concerns raised.

\section{DISCUSSION}

The four local authorities will be referred to as Council A, Council B, Council C and Council D.

Although these local government organisations have yet to adopt cloud computing they are fully aware of cloud services currently available and the development of government cloud (G-Cloud) from various government publications. In particular Council B has intentions to implement cloud computing with an SME cloud provider and has included this in their strategic plans.

A brief introduction to each of the participating councils is given below:

\section{Council A:}

Council A serves a population of 295,532 people, of which over 60 per cent are in employment with only 2.7 per cent registered unemployed. The council had a net budget of $£ 200$ million for 2012-13. Their strategic plan is to save more than $£ 30$ million over the three years to 2015 . This is in addition to the $£ 22$ million the council saved in 2011-12. Therefore in total the council will be saving $£ 50$ million over a four year period. The council has already cut staffing costs saving over $£ 3$ million. At the time of interview they were in discussion with surrounding councils to look at potential shared services. 


\section{Council B:}

Council B serves a population of some 247,000, according to the 2011 census data. Residents aged 25-49 count for more than $42 \%$ of this total, while residents aged 50 and over comprise a smaller amount of the whole borough population (23\%). The prevailing economic climate and central government funding cuts were placing considerable pressure on the council's budget, and this is likely to continue for the next few years. Efficiency savings had been a priority in addressing the budget cuts in order to minimise the effect on front-line services. Council B claims to be one of the first local authorities to be migrating email telephony and Microsoft technology to a cloud-based solution.

\section{Council C:}

Council $\mathrm{C}$ serves a population of over 300,000 , and has seen $6 \%$ population growth per annum since 1991. In that time the number of people aged below 16 has increased by $5 \%$. The council's diversity is high and has also increased in recent years, with over than $40 \%$ of residents being classified as minority ethnic compared with $9.1 \%$ nationally. One the council's priorities from financial year 2012-13 onwards has been to deliver value for money in response to funding cuts, with an objective to save $£ 85$ million by April 2015. The council has supported the concepts of opening up public information and providing public services online, and a range of electronic forms has been developed. The council has adopted a 24hour automated information service with the aim of reducing the need for unnecessary customer visits, with an appointment system for complex queries.

\section{Council D:}

Council D serves a population of approximately 150,000, and is one of the richest and most densely populated districts in the United Kingdom. Notwithstanding this demographic the council, in line with the rest of the public sector, has suffered cuts in central government grant. They were actively seeking means of reducing management and operational costs at the time of the interviews. A major aspect of this was seeking to establish a new relationship with surrounding boroughs in the shared delivery of council services. With an objective to reduce management costs in shared services by $50 \%$ the council was expecting to save a total of $£ 35$ million a year by $2014-15$. Council D adopts a hybrid approach to IT provision. Whilst the network server is developed and maintained in-house, many departmental information systems have been outsourced, one example being the human resources information systems. 


\section{Concept of Cloud Computing}

The notion that cloud computing is not clearly defined is confirmed by all four local authorities. The lack of a universally agreed definition of cloud computing is expressed by Council A, "I think the first thing is that cloud computing isn't clearly defined, what people mean by cloud computing, do they mean hosted solutions accessible via the internet? .... I think there's a lot of hype around it, without going into detail about what they actually mean by it". Similar to Council A, Council C is concerned that "different people are using that term and meaning different things" and staff in the IT department believe, from a technical point of view, that cloud computing is, in a sense, software as a service (SaaS) on a subscription basis, while Council D refers cloud computing as hosting services "with a different kind of name". Council B, sharing the same view as other participating councils, further indicates that because of the confusion about what is really meant by cloud computing it is unclear how much cloud computing and the G-Cloud will assist the council to achieve the substantial gains it promises.

\section{Background}

\section{Political}

All four councils disagreed with the notion that cloud computing is driven by Central Government's ICT strategies. The reasoning behind this is that, regardless of Government's ICT strategies and e-initiatives, local authorities have already been looking into ways of saving costs which always includes rationalisation options for their IT provision. In Council B's own words, cloud computing is driven by "the provision of more cost-effective services and the private sector responding to that business model or new business model which it is beginning to do at the minute...”. Similarly Council A believes that cloud's cost-saving abilities, and the potential to be 'infrastructure-free' are major advantages in terms of transforming the way the council operates and therefore it is an area that local government has been considering anyway, whether or not the Government had it in its IT strategy.

When asked specifically whether considering cloud computing has any correlation with the government's intentions to provide information and services online (Cabinet Office, 2010) the participants again disagree to some extent. Council B states that they can supply public service data online without necessarily subscribing to a cloud-based service, so the two are not inevitably linked. This argument is supported by Council C. Council D further explains that central government strategy is that by 2005 all services could be delivered electronically and that therefore local authorities - with this timeline in mind had done a considerable amount of work to support the strategy. So this does indicate some driving influence from central government. However, they had not actually implemented cloud computing at the 
time of interviews because, as Council D indicates, "we do have concerns over where our data would reside for some of our sensitive data".

There are differing opinions between the interviewees when considering if councils should specifically include moving to a cloud-based infrastructure of future IT provision in their ICT plans. Council B, in support of the government's cloud strategy, confirms that a cloud-based infrastructure is in the council's ICT strategy. Council A, on the other hand, maintains that the broader aims of reducing costs and increasing the flexibility of IT provision in future years are what are addressed in the council's strategic plans, and they are not convinced that cloud would be mature enough in the current strategic timeframe. Of the four participants only Council D agrees with the notion that the move to cloud-based IT provision and the development of G-Cloud come as a result of the Westminster government's intention to centralise IT resources. Aside from the issue of cloud computing, councils have already experienced the advantage of shared IT provision and recognise the need for collaboration among local authorities in a belief that it will lead to significant cost reduction and economies of scale. It is evident, according to Council A, that they have achieved a lower cost through jointly tendering for IT projects with a neighbouring council. Council $\mathrm{C}$ also points out that most local authorities are looking at ways of sharing their infrastructure or their key applications and hosted solutions, although again they do not consider such a practice to be cloud-driven.

\section{Economic}

All the participating councils have experienced significant cuts in IT budgets as a general result of the economic downturn of 2008 onwards, and specifically because of central governments ongoing tight public spending policies. Councils are proactively seeking ways of reducing IT costs and rationalising their existing infrastructure to sit within the available funding. With regard to cloud computing, however, Council A believes that G-Cloud is not the answer to the shrinking IT budget. The move to cloud-based services will make savings but it is not the only way of driving those savings. Conversely, savings may not be the only driver for change: Council $\mathrm{C}$ indicates that the council would not consider cloud computing purely for cost-saving purposes.

Although local councils generally support the development of the government cloud there is a level of suspicion in local government and the general attitude is to 'wait and see'. G-Cloud has been advocated by central government as an innovative ICT strategy for tomorrow's IT infrastructure model. The councils, however, consider both the innovation and the progress of the G-Cloud disappointing. According to Council D: “.... the whole G-cloud concept has been scaled back recently and kind of 
distilling down more to consolidating of data centres in the public centre really. Not much emphasis on the G-app side of it as there was before shall we say. .... I've attended various seminars, heard the spiel on G-Cloud, nothing much seems to be happening is my observation really, beyond the work they seem to be doing on data centre consolidation which seems generally sensible". The suspicion is that economic considerations have got in the way of central governments ambitious aspirations.

One of the held advantages of implementing cloud computing is that it is environmentally friendly and will reduce energy consumption in IT systems, therefore leading to reduced energy servicing costs (Vining \& Di Maio, 2009; AbdelSalam et al, 2009). While greener IT is a top priority for many local authorities (Foster et al, 2008) the participating councils do not think that adopting cloud computing on its own will reduce energy consumption much more than the IT practices they are already implementing. For example, Council B points out that the third-party data centre they use has greatly enhanced efficiency both in terms of virtualisation of servers and the environmental efficiency of cooling, heating and the use of electricity. The cost savings achieved through running a highly efficient data centre is also confirmed by Council $\mathrm{C}$ who own their own data centre and believe that they may not achieve any further cost savings by opting for an external cloud-based data centre. When asked about the G-Cloud, Council C felt that if it is built in an energy efficient data centre using virtualisation technology then it will use less energy. However, they are not sure whether this is in fact the case, at least not yet.

Council D, taking a slightly different view, emphasises that actual realised reductions is energy consumption will depend entirely on how efficient the particular cloud provider is. It is suggested that, "yes it would reduce our energy consumption and in terms of the carbon reduction commitment that would be good for us as an organisation, it would reflect well on us, ... on the eco friendliness shall we say, of the provider, ...to watch from a purist point of view of the environmental impact of what you're delivering as a business, ...so you do need to watch the provider and make that your criteria..." This response also points to the fact that green technology issues are not just relevant to authorities as an economic factor. There are also political and social considerations.

\section{Social}

In the literature there is a general assumption that the development of cloud computing or G-Cloud is derived from the concepts of 'commoditisation of government' and 'open government data' through the use of social media (Bertot et al, 2014; Di Maio, 2009). The participating councils disagree with this assumption, arguing instead that cloud computing has nothing to do with social media. They hold that the 
concept of allowing the general public to access public data through the Internet had been proposed a while ago, and therefore bears no direct connection with the move to cloud services.

It has been suggested that with their previous experience of outsourcing, SaaS (Software as a Service ) and virtualisation, local authorities would be well positioned to successfully implement cloud-based initiatives. From the case studies it is clear that local government does indeed have a great deal of experience in outsourcing. For example, Council A's IT infrastructure is heavily outsourced, including the IT helpdesk, servers and data networks and web-based back-up. Council C has virtually outsourced the entire IT management to a private sector service provider, and their applications run on hosted services from a variety of different vendors. When asked about implementing cloud computing from the perspective of building on their outsourcing experience, Council C said, "there's no great impediment to the council using cloud". However, as cloud computing and, more precisely, G-Cloud are still at an initial stage of development it seems from the interviewees that local authorities intend to wait until full benefits have been realised before considering implementation. As Council D comments, "We tend to be a risk averse organisation so we tend not to be on the leading edge, but we were an early adopter of virtualisation technology..."

\section{Technological}

It is held that one of the key features of cloud computing is simpler client-side infrastructure with a significantly reduced requirement for heavy IT investment, both hardware and upkeep costs (Han, 2013; Vaquero et al, 2008). This would be welcomed by local government when developing future IT strategies. After some years experience of outsourcing, the IT skills in Council B have been left undeveloped. There is therefore a 'skills gap' and the magnitude of that gap, or at least its significance as a problem, would be minimised by using cloud computing services and outsourcing various components on those services. Council D is the only one of the four case study participants to retain an in-house IT team. This team, they believe, has a lot of expert technical capability, so simpler infrastructure of itself would not be a factor to encourage them to move to cloud. That does not prevent them from considering cloud services for other reasons.

Flexibility is an important factor for local authorities when considering the cloud, specifically the ability to easily scale up and down the type and level of services provided sounds appealing (Herbst et al, 2013; McEvoy \& Schulze, 2008). Scalability means that if the council buys the IT infrastructure and has it for five years, and in that time the organisation shrinks, or some specific processes in the organisation shrink, then the council would need less of that infrastructure. In practice Council A predicts that identifying the 
level of infrastructure takes some 'intelligence around storage'. Local councils tend not to be that flexible. Most things are known in advance, so the cloud's flexible scalability is not a significant advantage to the council. Council B reaches a similar conclusion but via a different argument: they point out that one of the selection criteria in choosing a vendor is that if the service provider is incapable of meeting the council's needs and adjust the level of services quickly the council would not consider it. As the participating councils have yet to have substantial experience of cloud computing it is unclear to them how the 'scalability' feature will work for local authorities.

Local councils have had lots of experience in appraising and choosing external IT vendors through their outsourcing and SaaS practices. For example, Council A do not own in-house developers at all; they buy packages off the shelf and the application is customised according to requirements. As Council A comments, "the biggest challenge is to modernise line of business applications and some of the suppliers are quite slow in terms of responding to things". When asked how the vendors' experience would benefit the provision of cloud services, Council $\mathrm{C}$ points out that they would certainly expect cloud vendors to have more skills than their own staff which is one of the reasons for migrating.

\section{Driving forces}

\section{Cost savings}

As already mentioned, cost-saving is perhaps the most important factor driving local government to consider cloud computing since local authorities are currently under enormous pressure to find costeffective ways of restructuring IT infrastructure to reduce capital, servicing and staffing costs. Although none of the participating councils has fully implemented cloud computing it is felt that moving to cloudbased platforms and services brings the potential of massive savings. This supports Korri's argument (2009) that cloud computing presents an attractive alternative to building one's own computing infrastructure, which can be extremely costly.

Having already exhausted the cost saving potential of other IT changes it may be that councils now have to embrace cloud computing to realise the further savings demanded of them. Council A reveals that, "We run at very tight margins anyway and because we've been outsourced for a number of years so we've already taken the savings where we can. We've already cut quite a number of our costs through virtualization, through outsourcing, the rationalization of systems. I don't think there's a huge pot of money that we can save just because we're putting it out on the cloud but I'm hoping there's some savings there..... we’ve identified $£ 30 \mathrm{~m}$ worth of cuts which is approximately $20 \%$ of our overall budget. 
So staff will go, the numbers will be dramatically reduced, so how do you reduce staff without impacting the service, is self service the way to do it"?

Council B also predicts they could realise a cost saving of around $30 \%$ through cloud. Council C suggests that the G-Cloud would be potentially cheaper than using commercial cloud, and in addition it would be more secure. Council C's also see a double cost and security advantage in the G-Cloud; it could be seen as a secure private cloud, where councils share services with other local authorities, therefore achieving savings. It is built to be secure, because it is exclusively used by the public sector, which is a key factor for encouraging local government to move to cloud computing.

\section{Economies of scale}

If the G-Cloud is to offer a platform where public organisations and local authorities can share IT resources and key applications, then a high level of economies of scale can be expected through sharing data centres and centralising ICT facilities and expertise (Grossman, 2009; Kliazovich et al, 2013). Many local authorities have experienced savings from collaboration between IT departments and joint tendering for IT contractors. According to Council A, joined-up data centres can significantly reduce cost round data centres across government. In essence that is cloud at its most basic level providing hosted solutions. Using common applications that provide greater flexibility is another way of keeping IT costs to the minimum. Many IT initiatives and local partnership schemes have already encouraged local authorities to work together in sharing common platforms and networks.

\section{Strategic focus}

If local authorities no longer need to make large investments in IT infrastructure including hardware, software and staff then in theory considerable internal resource can be freed up (Aymerich et al, 2008). This enables the focus of attention and limited IT and human resources on 'mission-critical' areas (Low et al, 2011; Vining \& Di Maio, 2009). First of all, only Council B has specific plans to launch cloud initiatives and therefore the other three were unable to comment on this particular point. Secondly, in the current tight funding situation one intended outcome of local government's IT strategy is a conscious move to a much smaller IT infrastructure. So after downsizing it's questionable whether there will be significant resource available to strategically focus elsewhere. Thirdly, it is suggested that the staff remaining following a rationalisation process would need to be re-trained to support areas of strategic importance and their job descriptions will be significantly altered. 


\section{Resisting forces}

\section{Security and reliability of data}

Security and reliability of data are clearly a concern for local government when considering a move to cloud because of the confidential and sensitive nature of data being stored in the public sector (Younis and Kifayat, 2013; Buyya et al, 2009; Grossman, 2009). There is legislation in data security which impact on the adoption of cloud, for example, Council B stresses that, “... our information can't be hosted outside the country ... those set of considerations have to be brought to betterment; they're just as important as the reliability of the vendor or disaster recovery report, they all have to be right otherwise you wouldn't take the service out..."

With regards to how secure the data should be and how the level of safety can be measured, Council C explains: "Microsoft 365 is certified to impact level 2, protect level status as rated by CommunicationsElectronics Security Group (CESG) which means that it can carry personal information which if released incorrectly to the public domain might be an embarrassment but wouldn't cause harm. ... that is in effect G-cloud solution which is rated up to a higher security, that can carry confidential, secret information ... although it's fine for Data Protection Act purposes because it's inside the European Union, it means it's not likely ever to be rated more than IL2 by UK government, it's outside of their control".

Council A offers a different opinion about cloud security. The council is not worried too much about security because it is such an obvious issue that it will have to be taken care of by cloud vendors in due course, both private and G-Cloud. Security policies and disaster recovery strategies are very much dependant on the reliability of the vendor and the contract negotiations (service level agreement). This argument is supported by Council D.

\section{Privacy and access}

In a similar way to their views on the security and reliability of data, the participating councils are not particularly concerned about privacy of and access to data. Council A explains that, "I'm not so concerned about privacy and similar issues etc. because they're so obvious. Those are sort of hygiene factors I would absolutely expect them to be taken care of'. Local councils have already had policies and strategies in place to ensure individual privacy, data security and information assurance, and now have vast experience in dealing with these issues at all scales.. Council D expresses the same level of confidence commenting that, "Individual privacy I see that probably more of a perception of a problem rather than a real problem ....providing that you choose your vendors well it didn't ought to be a problem, because you know it would bad for their business if it was". These are seen to be such obvious stumbling 
blocks for the whole concept of cloud computing that the councils assume that the technical issues will have to be solved.

\section{Service level agreements}

As previously discussed, realising the potential benefits of cloud services very much depends on the detail of the Service Level Agreements (SLAs) drawn up between vendor and client. Council B provides a detailed account of what should be considered and included in a SLA, which is an important task for local authorities managing IT projects of outsourcing, SaaS and cloud: “... you can make assessment based on experience and knowledge, use that as a basis... but the whole field of defining an SLA and penalty clauses is very difficult one to do in any commercial contract because of course the supplier will construct that, see the penalty clauses that will be extremely difficult to ever implement or ever come into effect... there has to be clauses and definitions within the contract which negate and define what security the data is, we have to analyze the financial viability of the vendor to make sure that the supplier of those services is financially secure and able to continue to provide those services for the length of the contract. ...what the levels of access will be for that data and how will that data be protected". Local government works in a strict regulatory framework and is required to scrutinise and audit to a high level when spending public monies. This will impact on the drafting of the SLA.

\section{Internet-related issues}

Internet speed and bandwidth-related issues are held to be a concern when services are provided entirely through the Internet (Grossman, 2009). As Council D comments, “... when you were looking to go to cloud route for service you would obviously be looking at your network band capabilities and you could upgrade that capability if you needed to deliver through a provider or use efficiently through cloud mechanism. So it's just a cost factor to bear in mind if you're heading down a cloud route for something which you may need to upgrade your network bandwidth capability". The attitude of the council is not so much that this could be a resisting force, but that it is certainly a technical and cost issue to be addressed in the consideration and implementation of cloud computing.

\section{Implementation issues}

\section{Business process change}

A number of business process change related issues have been identified by the participating councils. In general terms, however, it is felt that moving to a different business model of public services is very much an evolutionary, rather than revolutionary process. For example, Council A believes that the IT departments in local government will inevitably be downsized due to the need to rationalise business 
applications. This will not happen overnight but through a planned, staged approach to business process change.

Council B gives some forecast as to what will be changed in the next five to six years, “... we're moving our infrastructure to third parties, ...the CIO, the IT director, will become much more of a commissioner of services rather than runner of internal services or manager of internal services, defining those requirements and working with businesses technology partner and then procuring those services through the most cost-effective means which might mean full scale out-sourcing, through the third party, it could be considerable, substantial outsourcing and anything in-between depending on the needs of the organization".

Similarly Council D predicts the council to be of "fewer staff, ultimately... savings don't come in a sort of linear way, they come in a step way when it comes to staffing so initially I would see in the early days just a few services you'd probably make very little difference". The job descriptions of the existing IT staff would be significantly different. They would not be doing things such as storing and looking after databases. When cloud has become a commonly used platform in local government IT professionals will need to be re-trained and move to different areas and do whatever is required. Again, Council D supports the idea that the outlook and activities of the IT department will be altered but this will change gradually, not radically.

\section{Project management and planning}

The four councils were asked to comment on project management in relation to cloud computing, considering the role both of central government and of local authorities. Adequate project management and planning skills are held to be critical to the successful development and implementation of G-Cloud, for which the government has adopted a staged approach. According to Council A there is a history of unsuccessful IT projects and contract negotiations in the public sector (cf. Gilbert, 2009; Sandeep and Ravishankar, 2014). This explains a delay in central government advocating its G-Cloud to local authorities. Council D shares the same view, indicating that, “...I can't see that [G-cloud] happening at the moment. G-Cloud doesn't seem to be delivering anything useful yet”. The issue of G-Cloud delay should also be considered in the context of reduced public funding as already discussed.

Regarding the success or failure of IT projects in local government specifically, Council C admits that failures are mostly likely for those projects where the council has attempted to develop applications inhouse. As the head of IT comments, “...I doubt you'll find any development of specific coding going on, 
council can't afford it; too risky and incidents of projects failing are too high". The participating councils tend to agree that the success of providing cloud-based IT provision in local government relies mainly on the selection of vendors and contract negotiations. As noted already, councils have experience in managing outsourcing and SaaS contracts, but the interviewees suggest specific project management and planning skills required for the transition from traditional IT provision to cloud-based infrastructure need to be further identified.

\section{Information assurance and governance}

As already discussed, security and privacy will be a concern for local government when considering cloud-based services, although local authorities are very aware of information assurance and governance issues and are familiar with the relevant legislation. Council B mentions GCS6 standards where the council has encrypted laptops so that if they are lost the data will not be accessible. They emphasise that they cannot adopt cloud computing if the cloud service is not compliant with GCS6. Cloud vendors will have to provide some assurance in the SLA (Kandukuri et al, 2009; Moreno-Vozmediano et al, 2013). "If you start to house some of that data in the cloud you may have some problems with complying with that

...” As regards individual privacy, Council C argues information assurance and data security "are all part of any procurement we would do, they would be key requirements for whether it was cloud, traditional hosting or in-house. They are core considerations and they would be part of the evaluation process".

\section{Choices of vendors, products and approach}

A number of issues are addressed in the conceptual framework regarding the implementation of cloud computing: selection of vendors, vendor lock-in, approach and methods. The participating councils were invited to comment on these issues. When asked how to choose a vendor Council A provided the criteria that would be adopted by the council: functionality and price. This is similar to how Council D would select a cloud provider. However, Council D indicates that there should be a different cost model used for cloud services, taking into consideration revenue, budgets and the council's own operating costs. Council $\mathrm{C}$, on the other hand, advises that they would select vendors through a competitive procurement process, just like any other types of procurement. EU and UK public sector procurement rules would in any case apply to any large competitive tender for supplying cloud services.

An interesting perspective is offered by Council B: in choosing a cloud partner they would go for medium-sized service providers, "big enough to meet our needs, small enough for us to be their significant client”. An explanation is given, “... So that's the key principle going forward with our 
vendors, as we form partnership with them and we choose vendors that are the right size and the right flexibility to meet our needs".

Vendor lock-in is a concern, shared by all four councils. As Council A raises, "what would stop the vendor from pushing their prices up because I can't walk away very easily and because I wouldn't have

local infrastructure anymore. So there really has to be tight contracts negotiated there". Moving from one supplier to another can be costly (Buyya et al, 2008; Satzger et al, 2013). This includes the cost of changing the technology once a vendor discontinues the service (Foster et al, 2008). Without the IT infrastructure, a key resource, can lead to a loss of organisational control, as warned by Buyyaet al (2008). For this Council B proposes that a contract should be formulated "in the term that you want to have the right exit strategy in it... and that there are lots of protection and procedures to make migrating commoditised service from one supplier to another relatively straightforward".

Another implementation issue is integration with existing IT infrastructure, considered the biggest challenge by Council A. As previously mentioned local authorities are relatively conservative and are likely to employ a hybrid and staged approach to cloud computing (Di Maio, 2009; Leavitt, 2013). Such an attitude is evident in Council B's plans to implement cloud computing: "We'd like other people to take the risk first and depending on how they go, then we go for it" As with all public sector IT rationalisations (and also often in large private sector organisations) choice of product and supplier has to take account of the existing infrastructure and processes. There is just not the money available to go for an idealised 'everything new' strategy. Certain otherwise attractive suppliers may need to be discounted if they cannot hybridise with the authority's existing systems.

\section{FUTURE RESEARCH DIRECTIONS}

This explorative study is based around the viewpoint of four urban local authorities, each based in London, close to central government and other national resources and with large, dense and mobile populations. Future research can build on the findings from the present study to include councils with alternative geographical and demographic characteristics, whose views might be substantially different. Including views from authorities situated in rural areas would be especially relevant, as IT resources and skills might not be readily available, and the required council service outcomes may be very different. Interviewing a greater range of stakeholders such as IT directors, senior managers, IT technicians and users from different departments would also enrich the study, adding depth to the findings. A quantitative survey would be beneficial as concepts and beliefs can be generalised. The framework can also be 
expanded to include success/failure factors once enough local authorities have considered and implemented cloud computing.

Taking the study in a different direction, future research can adopt a longitudinal approach by undertaking an in-depth case study with a single council which has had a full experience in utilising the G-Cloud framework. In this way the issues identified in the current conceptual framework can be investigated in greater detail. This may involve looking into the physical design and implementation of a cloud-based infrastructure, the approach, type and business model used to integrate cloud with existing systems, an analysis of cost savings in financial terms, the impact of cloud on the authorities existing and future business and IT strategies, methods used by the council for monitoring and 'lessons learned', and how central government has supported the G-Cloud.

\section{CONCLUSION}

A conceptual framework is proposed by Chang (2011) to help analyse the impact of implementing cloud computing in local government. Key issues are identified in the framework, which form the basis for the present research to gauge the general attitude and perceptions of local authorities towards the application of cloud-based services. The importance of the subject area is justified by the UK government's ICT strategies and staged plans to implement the government cloud (G-Cloud) (Cabinet Office, 2010). The research attempts to investigate to what extent local authorities are aware of cloud computing and the development of G-Cloud, the main benefits, as well as constraints of adopting cloud computing to local councils and any concerns regarding implementation, in terms of business process change, relationships with cloud providers and issues relating to data security and information assurance. A case study methodology has been adopted because the subject area is relatively new. Four London-based borough councils are chosen and interviews of senior members of staff from both IT and business departments are carried out. Their views and opinions are analysed and compared which shed a light into the current strategies and future plans for cloud services and the G-Cloud.

There is no precise definition of cloud computing, a notion that has been confirmed by the case study organisations who offer views about what cloud computing is. It can be suggested that many current IT practices, such as SaaS, hosted services and virtualisation, form part of the so-called cloud computing. In fact, most local councils now do not have in-house developers. Public services are provided mostly online and much of the IT services are outsourced. There is need for clear and universally agreed definitions of cloud computing for the purposes of academic discussion and practical guidance. 
There is only one council that supports the government's cloud strategy and has intentions to implement cloud computing in the near future. Other councils would prefer to wait until there is a clear evidence to suggest that all benefits of cloud computing can be realised. Such an attitude comes from local authorities being relatively cautious and conservative in adopting new ways of providing public services, and riskadverse so that it is unwise to be the first to implement cloud computing.

Contrary to the belief that the move to cloud services is largely driven by the government's central ICT strategies, case organisations disagree that there are specific instructions from the government to implement G-Cloud. Local government are proactively seeking ways of reducing management and operational costs, due to decreasing grant and budgets, and many local councils have already undertaken measures to ensure that considerable savings can be made in the coming years. These include using the most energy-efficient data centres, providing public services online, collaborating with surrounding councils for shared IT systems and rationalising the existing IT infrastructure, whether cloud-based or not. The view from the participating organisations is clear: cloud computing has a potential in helping councils to reduce costs but it is not the only answer to the economic downturn and reduced funding. Savings on, for example energy consumption, will depend on how efficient the cloud provider is. It has been suggested that cloud computing is driven by the government's intension to commoditise public information and services. And the development of government cloud is linked to the prevalence of social media and Internet technologies. These views are not specifically supported by the participating councils. On the other hand, local authorities have had many years of experience in outsourcing and using external service providers to customise applications based on requirements. Local authorities are aware that considerable savings can be achieved by employing virtual servers and web-based storage and recognise the importance of negotiating with vendors for a well-balanced SLA. A more serious concern, vendor lock-in, is shared by the case organisations because the promised benefits of moving to cloud could be compromised once the cloud provider is responsible for the entire IT infrastructure and demands a higher price. Local government is urged to think carefully about 'exit' strategy and rules and procedures to be included in the contract when formulating SLAs.

Cloud computing will transform the council's IT infrastructure, business processes and how the services are provided. Although not asked specifically about downsizing the participating councils admit that due to the economic downturn and the enormous pressure arising from reduced public funding local government has 'staged' plans for a much smaller-scaled IT department, self-service online facilities and collaboration between local authorities. IT directors will be more concerned about commissioning work 
and negotiating SLAs. The impact of such business process change to existing staff and job descriptions need to be investigated further.

One of the major concerns in cloud computing is data security, privacy and access. The requirement to host sensitive data in the country will prevent local authorities from considering cloud services because there are certain laws and regulations councils need to comply with, for example, those governed by the CESG. This concern may be overcome by the adoption of the G-Cloud which is developed by central government with adequate security measures that will satisfy legal requirements. In fact, local authorities already have strict information governance policies and strategies in place. They are not too concerned about data security and individual privacy when considering cloud because it is an obvious issue that would be taken care of by the service provider. Similarly, technical issues such as Internet speed and network capabilities should not be a problem, because they can be easily assessed and dealt with if councils are to adopt cloud services.

\section{REFERENCES}

AbdelSalam, H., Maly, K., Mukkamala, R., Zubair, M. \&Kaminsky, D. (2009). Towards energy efficient change management in a cloud computing environment, AIMS, 161-166.

Amazon. (2010). Amazon elastic compute cloud, Retrieved February 15, 2010 from www.amazon.com.

Armbrust, M., Fox, A., Griffith, R., Joseph, A. D., Katz, R., Konwinski, A., \& Zaharia, M. (2010). A view of cloud computing. Communications of the ACM, 53(4), 50-58.

Aymerich, F. M., Fenu, G., \& Surcis, S. (2008). An approach to a cloud computing network. In 1st International Conference on the Applications of Digital Information and Web Technologies, 113-118, August 2008

Bertot, J. C., Gorham, U., Jaeger, P. T., Sarin, L. C., \& Choi, H. (2014). Big data, open government and e-government: Issues, policies and recommendations. Information Polity, 19(1), 5-16.

Bojanova, I., Zhang, J., \& Voas, J. (2013). Cloud computing. IT Professional, 15(2), 12-14. 
Buyya, R., Yeo, C.S., \&Venugopal, V. (2008).Vision, hype and reality for delivering IT services as computing utilities. In 10th IEEE International Conference on High Performance Computing and Communications, 5-13, September 2008

Cabinet Office, (2010). Government ICT Strategy: smarter, cheaper, greener, London: Cabinet Office, January 2010

Catteddu, D. (2010). Cloud Computing: benefits, risks and recommendations for information security, 17 17, Berlin Heidelberg: Springer.

Chang, J. A framework of analysing the impact of cloud computing on local government in the UK, International Journal of Cloud Applications and Computing, 1(4), 25-33, October-December 2011. Das, R. K., Patnaik, S., \& Misro, A. K. (2011). Adoption of cloud computing in e-governance. In Advanced Computing (pp. 161-172). Berlin Heidelberg: Springer.

Digital Britain, (2009). Final report, presented to Parliament in June 2009, London: The Stationery Office.

Di Maio, A. (2009). Cloud computing in government: private, public, both or none? Gartner, June, 2009

Di Maio, A. (2009). GSA launches Apps.gov: what it means to government IT leaders? Gartner, September 2009

Di Maio, A. (2009). Government in the cloud: much more than computing, Gartner, June 2009

Foster, I., Zhao, Y., Raicu, I., \& Lu, S. (2008). Cloud computing and grid computing 360-degree compared, in Grid Computing Environments Workshop, 1-10, November 2008

Grossman, R.L. (2009). The case for cloud computing, computer.org/ITPro, IEEE Computer Society

Han, Y. (2013). On the clouds: a new way of computing. Information Technology and Libraries, 29(2), 87-92. 
Herbst, N. R., Kounev, S., \& Reussner, R. (2013, June). Elasticity in Cloud Computing: What It Is, and What It Is Not. In ICAC, pp. 23-27.

Kandukuri, B. R., Ramakrishna, P.V., \&Rakshit, A. (2009). Cloud security issues, In the 2009 IEEE International Conference on Services Computing, 517-520.

Kliazovich, D., Bouvry, P., \& Khan, S. U. (2013). Simulation and Performance Analysis of Data Intensive and Workload Intensive Cloud Computing Data Centers. In Optical Interconnects for Future Data Center Networks, 47-63, New York: Springer.

Korri, T. (2009). Cloud computing: utility computing over the Internet, Seminar on Internetworking, Helsinki University of Technology, April 27, 2009.

Leavitt, N. (2013). Hybrid clouds move to the forefront. Computer, 46(5), 15-18.

Luis, M.V., Luis, R, Caceres, J., \& Lindner, M. (2008). A break in the clouds: towards a cloud definition, SIGCOMM Computer Communication Review, 39(1), December 2008

Maggiani, R. (2009). Cloud computing is changing how we communicate, IEEE Explore, November, 2009

Lewin, K. (1947). Frontiers in group dynamics: concept, method, and reality in social science, Human Relations, 1(1), 5-42.

Low, C., Chen, Y., \& Wu, M. (2011). Understanding the determinants of cloud computing adoption. Industrial management \& data systems, 111(7), 1006-1023.

Marston, S., Li, Z., Bandyopadhyay, S., Zhang, J., \& Ghalsasi, A. (2011). Cloud computing-The business perspective. Decision Support Systems, 51(1), 176-189.

Mell, P., \& Grance, T. (2009). The NIST definition of cloud computing. National Institute of Standards and Technology, 53(6), 50. 
McEvoy, G.V. \& Schulze, B. (2008). Using clouds to address grid limitations, In $M G C$ '08: proceedings of the 6th international workshop on Middleware for grid computing, 1-6, New York: ACM.

Mishra, A., Mathur, R., Jain, S., \& Rathore, J. S. (2013). Cloud Computing Security. International Journal on Recent and Innovation Trends in Computing and Communication, 1(1), 36-39.

Moreno-Vozmediano, R., Montero, R. S., \& Llorente, I. M. (2013). Key challenges in cloud computing: Enabling the future internet of services. Internet Computing, IEEE, 17(4), 18-25.

Nelson, M.R. (2009). The cloud, the crowd and public policy, Issues in Science and Technology, Summer 2009, 71- 76.

O'Donnell, M. and Stewart, J. (2007). Implementing change in the public agency/leadership, learning and organisational resilience, International Journal of Public Sector Management, 2007, 20(3), 239-251. Plummer, D.C., Smith, D.M., Bittman, T.J., Cearley, D.W., Cappuccio, D.J., Scott, D., Kumar, R., and Robertson, B. (2009). Five refining attributes of public and private cloud computing, Gartner, May 2009.

Sandeep, M. S., \& Ravishankar, M. N. (2014). The continuity of underperforming ICT projects in the public sector. Information \& Management, 51(6), 700-711.

Satzger, B., Hummer, W., Inzinger, C., Leitner, P., \& Dustdar, S. (2013). Winds of change: From vendor lock-in to the meta cloud. IEEE internet computing, 17(1), 69-73.

Scholl, H. J., \& Klischewski, R. (2007). E-government integration and interoperability: framing the research agenda. International Journal of Public Administration, 30(8-9), 889-920.

Silva, G. C., Rose, L. M., \& Calinescu, R. (2013, December). Towards a Model-Driven Solution to the Vendor Lock-In Problem in Cloud Computing. In Cloud Computing Technology and Science (CloudCom), 2013 IEEE 5th International Conference on. 1, 711-716.

Takabi, H., Joshi, J. B., \& Ahn, G. J. (2010). Security and Privacy Challenges in Cloud Computing Environments. IEEE Security \& Privacy, 8(6), 24-31. 
Thomson, R. (2009). Socitm: Cloud computing revolutionary to the public sector, Computer Weekly, 24th of February 2009.

Tsohou, A., Lee, H., \& Irani, Z. (2014). Innovative public governance through cloud computing: information privacy, business models and performance measurement challenges. Transforming Government: People, Process and Policy, 8(2), 6-6.

Vaquero, L. M., Rodero-Merino, R., Caceres, J., \& Lindner, M. (2008). A break in the clouds: towards a cloud definition, SIGCOMM Computer Communication Review, 39(1), December 2008.

Vining, J. \& Di Maio,A. (2009). Cloud computing for government is cloudy, Gartner, February 2009.

Wyld, D. C. (2010). The Cloudy future of government IT: Cloud computing and the public sector around the world. International Journal of Web \& Semantic Technology, 1(1), 1-20.

Yin, R. K. (2009). Case Study Research: Design and Methods, California: Sage Inc.

Younis, M. Y. A., \& Kifayat, K. (2013). Secure cloud computing for critical infrastructure: A survey. Liverpool John Moores University, Liverpool: Tech. Rep.

\section{KEY TERMS AND DEFINITIONS}

Business process change: Business process change refers to a planned programme to redesign, update or integrate an organisation's business processes in order to achieve its business objectives. This may be in response to a specific change in the organisations business operating environment. It is an actively planned and analysed process enabling the organisation to re-think linkages between strategy, business processes and people.

Cloud computing: Cloud computing refers to a scalable network infrastructure where consumers receive IT services such as software and data storage through the Internet on a subscription basis, like traditional utilities. Potential benefits include cost savings, simpler IT and reduced energy consumption. Areas of concern include security, access, data protection and ownership. 
Data centre: A data centre is a facility that houses and maintains computer, server and networking systems and their components as part of a company's IT infrastructure. In cloud computing the data centre is owned by the cloud service vendor.

Government cloud (G-Cloud): The Government cloud in the UK, or G-Cloud, is an initiative developed by the central government to simplify the cloud procurement process for public organisations. The G-Cloud is a series of framework agreements with suppliers, from which public sector organisations can obtain services without needing to run a full, lengthy and complex tendering process. There is an online store called the "CloudStore" that allows public sector bodies to search for services that are approved by the G-Cloud frameworks

IT infrastructure: IT infrastructure refers to the set of IT hardware, software, networks and supporting facilities used by an organisation to develop, test, deliver, monitor, control or support IT services. It should be noted that users, processes and documentation are not part of the IT Infrastructure.

Outsourcing: Outsourcing is the practice whereby a business process is carried out by a vendor or service provider external to the client organisation. There are different types of outsourcing; sometimes it involves employees of the service provider working in the client company, or the other way round. It sometimes involves relocating a business function to another country to take advantage of lower labour rates. This is called offshore outsourcing. Cost savings are the main incentive to outsource business processes.

SaaS: Software as a Service, or SaaS, is a model of cloud computing in which software is licensed on a subscription basis. The term is sometimes referred as 'on-demand software'. The SaaS provider gives on-demand support to users and is responsible for software maintenance and upgrades. One of the selling points of SaaS is the client firm's reduction in IT support costs through outsourcing hardware and software maintenance to a reputable provider. 
Service level agreements: A service-level agreement is an agreement between the client organisation and the service providers. It is the contract between two or more parties setting out the agreed services, performance measurement, timescales, warranties, disaster recovery and agreement termination procedures.

Vendor lock-in: Vendor lock-in is a business practice whereby a service provider can make the client organisation solely dependent on them for a product or service, unable to user other vendors without paying substantial switching costs. This practice is sometimes referred as proprietary lock-in or customer lock-in. The behaviour itself encourages a monopoly in a market or industry.

Virtualisation: Virtualization is normally referred to creating a virtual, as opposed to actual version of a resource or device, such as a storage device, server, network or even an operating system. For example, server virtualization enables PCs to run multiple operating systems or applications making the IT infrastructure simpler and more efficient. 